\title{
The Use of Lecture Capture and Student Performance in Physiology
}

\author{
Rim Mekonnen Hadgu ${ }^{2}$, Sophia Huynh ${ }^{2}$ \& Chaya Gopalan ${ }^{1,2, *}$ \\ ${ }^{1}$ Departments of Applied Health \& Nursing, Southern Illinois University Edwardsville, Illinois, USA \\ ${ }^{2}$ St. Louis College of Pharmacy, St. Louis, Missouri, USA \\ *Correspondence: Departments of Applied Health \& Nursing, Southern Illinois University Edwardsville, IL \\ 62026-1049, Campus Box 1126, USA. Tel: 1-618-650-5372. E-mail: cgopala@siue.edu
}

Received: December 12, 2015 Accepted: January 16, 2016 Online Published: February 15, 2016

doi:10.5430/jct.v5n1p11

URL: http://dx.doi.org/10.5430/jct.v5n1p11

\begin{abstract}
Lecture capture technology is fairly new and has gained interest among higher institutions, faculty and students alike. Live-lecture (LL) is captured in real-time and this recording, LC, is made available for students to access for later use, whether it be for review purpose or to replace a missed class. Student performance was compared between those attending LL only and the other group utilizing LC in addition to LL in two randomly chosen lectures. We found that the overall exam performance was indistinguishable between the LL and the LC groups. Additionally, there was no significant difference in student performance between the two groups on questions that originated from these two lectures. Subsequently, the exam questions that came from these two lectures were separated into three Bloom's levels: memorization questions (MQ), comprehension questions (CQ), and application questions (AQ). Once again, there was no significant difference between these three tiers of questions. Additionally, we explored whether it is students with higher grades or lower grades in this course that were viewing LC and found that there was no correlation. This study thus suggests that LC is utilized by students of all grade levels but its exploitation is not associated with a grade enhancement at distinctive Bloom's levels.
\end{abstract}

Keywords: live-lecture; lecture capture; student performance

\section{Introduction}

Over the last few decades, the traditional classroom has been experiencing a rapid growth in educational technology, which enables educators to help students explore content in diverse modes. The complex concept of the "classroom" has expanded beyond four walls as students are able to access lectures in digital format from any location (Frey, 2011, Marchand, Pearson, \& Albon, 2014, Newton, Tucker, Dawson, \& Currie, 2014). The implementation of newer educational tools by higher institutions has made it possible for instructors to provide real-time recordings of live-lecture (LL) that can be used to review content or to replace missed lecture.

Lecture capture (LC), the real-time recording of LL, can offer distant learning and serve as an additional resource for students struggling with language barriers as it allows students to be self-paced and self-disciplined in a more learner-oriented manner (Euzent, Martin, Moskal, \& Moskal, 2011, Frey, 2011, Newton, Tucker, Dawson, \& Currie, 2014). Faculty members utilizing this technology facilitate learning by allowing students to access their real-time recordings and in turn benefit from being able to obtain information for course improvement based on the data of the topics students accessed more due to the level of difficulty (Prodanov, 2012). Despite these advantages, instructors have often shown reluctance in implementing LC because of a potential correlation with student absenteeism (Maynor, Barrickman, Stamatakis, \& Elliot, 2013, Prodanov, 2012). One of the student survey responses showed that the largest majority of students commonly viewed LC videos to revisit difficult concepts discussed in LL and expressed that LC did not replace LL. Moreover, student absenteeism was markedly small (Marchand, Pearson, \& Albon, 2014). Other studies, on the other hand, have shown higher dropout rates among online students than LL students (McLaren, 2004, Navarro, 2000).

At present, the influence of LC on student outcome has no uniform consensus (Euzent, Martin, Moskal, \& Moskal, 2011, Secker, Bond, \& Grussendorf, 2010, Stroup, Pickard, \& Kahler, 2012). While some studies have shown that LC provides little to no grade improvement when combined with LL (Brotherton, \& Abowd, 2004, Karnad, 2013, McLaren, 2004, Navarro, 2000), other studies have shown that LC significantly improved student performance and 
retention when it was used to supplement LL (Cramer, Collins, Snider, \& Fawcett, 2007, Danielson, Preast, Bender, \& Hassall, 2014, Secker, Bond, \& Grussendorf, 2010, Whitley-Grassi, \& Baizer, 2015). Whether LC improves student performance and more specifically which group of students, either the upper half of the class or the lower half of the class that would benefit from LC was explored in this study. Additionally, we explored whether LC would be beneficial at the factual detail level of Bloom's taxonomy versus the higher application level of understanding.

\section{Methods}

Sixty-three undergraduate lower division Introductory Physiology students at St. Louis College of Pharmacy, 39 females and 24 males, ages 18 to 21, submitted their informed consents to take part in this study. The number of male and female students participating in the study matched the class ratio of $60 \%$ female to $40 \%$ male students. Students were enrolled in this course for the first time after they completed a pre-professional sophomore level Anatomy course at the college. The entire course was taught by the same instructor and this course was held during a regular semester of 16 weeks where the class met for 50 minutes, three days a week. Students were provided with a lecture outline that consisted of objectives as well as a brief description related to each topic which would be further elaborated during lecture. The lecture typically involved explanation of the topics using images in the PowerPoint slides as well as quick drawings using document camera. Students were also given review questions to complete on their own. In addition to lectures, there were group activities scheduled typically before the unit exam with the intention of reviewing the topics in the form of application questions. The instructor also offered an additional review session immediately before each exam during a mutually convenient time outside of regular class period that was attended by majority of the class.

\subsection{Consent Forms}

Upon approval of the project by the Institutional Review Board, written consent forms were distributed to the class size of 91 students, among which 63 students participated in this study (69\%). Students submitted their signed consent forms to the Administrative Assistant in the department who stored them until the final grades were submitted. Student names and identification numbers were replaced by numeric codes prior to data analysis.

\subsection{Study Design}

Lecture objectives and study guides were made available on the Moodle course page. Students were expected to complete reading assignments prior to class to prepare for daily quizzes that covered the reading assignment as well as topics the instructor discussed in the previous lecture. According to records maintained by the teaching assistants, the class had perfect attendance except on rare occasions. Additionally, student access to internet was blocked in anticipation of decreasing distractions related to social media and/or online video games. Furthermore, cell phone usage in class was also restricted. Lectures were given live and captured by the hardware-software system, Panopto. LCs consisted of screen capture of both the computer and the document camera. Each recording was uploaded automatically to the course page as soon as the class period ended and remained accessible until the end of the semester. These recordings were approximately 40 minutes long. The Introductory Physiology course was the first time these students utilized lecture capture technology.

Two randomly selected lectures, one lecture on the physiology of blood and the second on the digestion in the upper gastrointestinal tract, were used to evaluate LC impact on student performance. First, we compared the overall exam grades of students from the LL and LC groups. We then separated the questions that came from the two selected LCs from the exams. There were a total of 21 questions from the two lectures that were used in the comparison. The exam consisted of questions to test factual detail (memory questions; 50\%), comprehension (35\%) and application (15\%) skills. The 21 questions were subdivided into MQ, CQ and AQ and compared student performance on these questions in the LL and LC groups. Finally, the class grade was separated into above $50^{\text {th }}$ percentile and below $50^{\text {th }}$ percentile and compared the student performance within this category (Figure 1).

The course management system, Moodle, and Panopto, the hardware-software system that allows lecture recording, video streaming and video content management, was used to track the duration as well as the number of times of viewing that was required to conduct this study. The settings were such that the recorded videos were in a streaming format and not available for download to enable accurate viewing analytics. The students who only attended LL, but did not access the live recordings of lecture comprised our LL group while students who attended LL and accessed lecture-captured videos constituted our LC group. From the data we collected, it was evident that there was a wide range among the students who accessed the lecture recordings: students either watched a majority of the video, multiple times of the same video or viewed only small snippets. In order to be in the LC group, students must have watched at least $50 \%$ of each video. Students who did not meet this criterion were treated as LL students and were 
included in the analysis as such. Students were grouped independently for each video. Thus the sorting of groups took place based on students' viewing data.

There were altogether five unit exams and a final comprehensive exam. Exams were scheduled approximately three to four weeks apart and each exam was worth $10 \%$ of the students' final grade. The comprehensive exam was given during the finals week and was immediately after the fifth exam. Students who earned an average of at least $85 \%$ in the previous exams were exempt from their comprehensive final. Neither of the exams that were utilized in this study were comprehensive exams. Each exam included material since the last exam and consisted of 50 multiple-choice questions that were divided into the following categories by the level of difficulty: Memory Questions (MQ), Comprehension Questions (CQ), and Application Questions (AQ). Memory questions referred to the retrieval of factual details, comprehension questions composed the intermediate level in reference to Bloom's taxonomy, and the application/analysis questions were considered the higher order questions (Bloom, 1956).

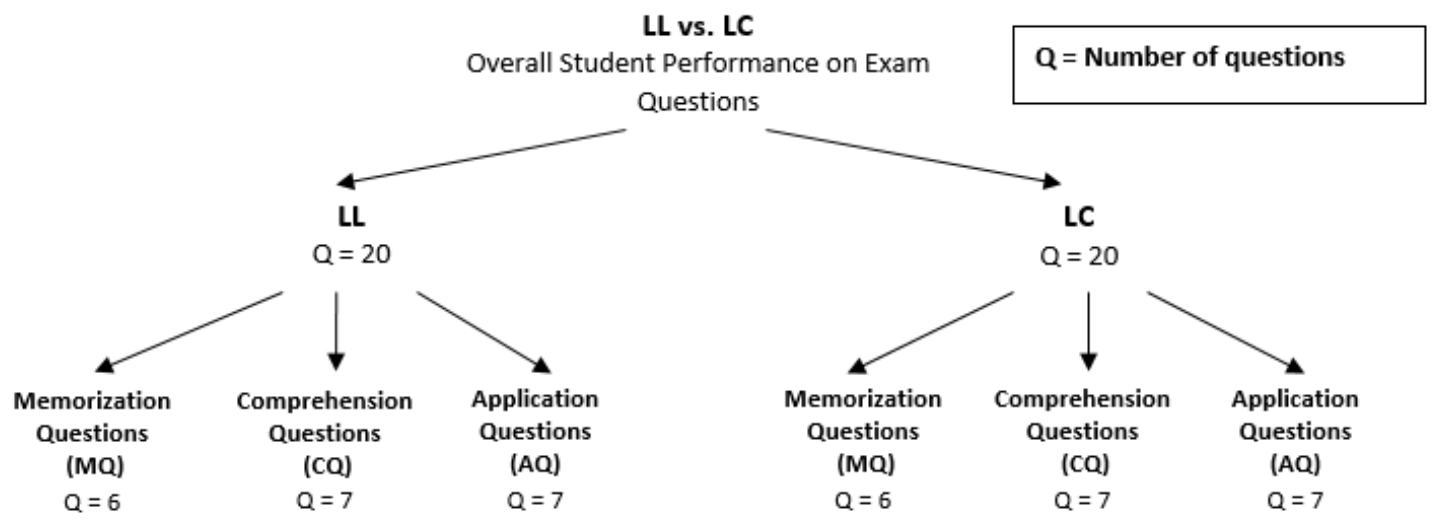

Figure 1. Study Design: Comparison of Student Performance between Live Lecture (LL) and Live and Recorded Lecture (LC)

\subsection{Statistical Analysis}

Group differences in test performance were assessed with a test of proportions, while comparisons of the patterns of the results used the Man-Whitney U test (Figure 3). For all comparisons, $\alpha<0.05$ was considered to indicate statistical significance. Additionally, one-way analysis of variance (ANOVA) with appropriate post-test was applied where necessary (Figures 2 and 4). A two-tailed t-test was used for the scatter plots (Figures 5-8).

\section{Results}

\subsection{Overall Individual Student Performance on Exam Questions}

Only $30 \%$ of students accessed the recorded lectures for this study. When the student performance on the individual questions that originated from these two lectures was compared, LL students had an average of $78.4 \%$ of exam questions correct while LC students had an average of $77.1 \%$ (Figures $2 \& 3$ ). However, there was no significant difference between these two groups. Additionally, the pattern of test performance was the same in both groups (Figure 3) where $85 \%$ of students scored above $70 \%$ for LL and $79 \%$ for LC. There was no significant difference between these groups also. 


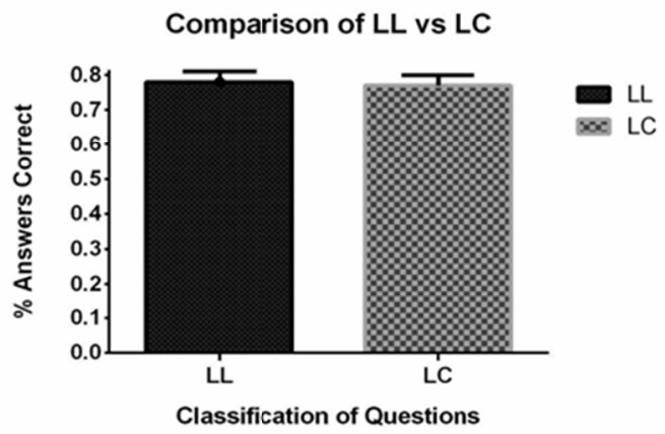

Figure 2. Individual Student Performance on Exam Questions ( $N$ for $L L=80$ between two lectures, $N$ for $L C=46$ between two lecture videos; One-way ANOVA test).

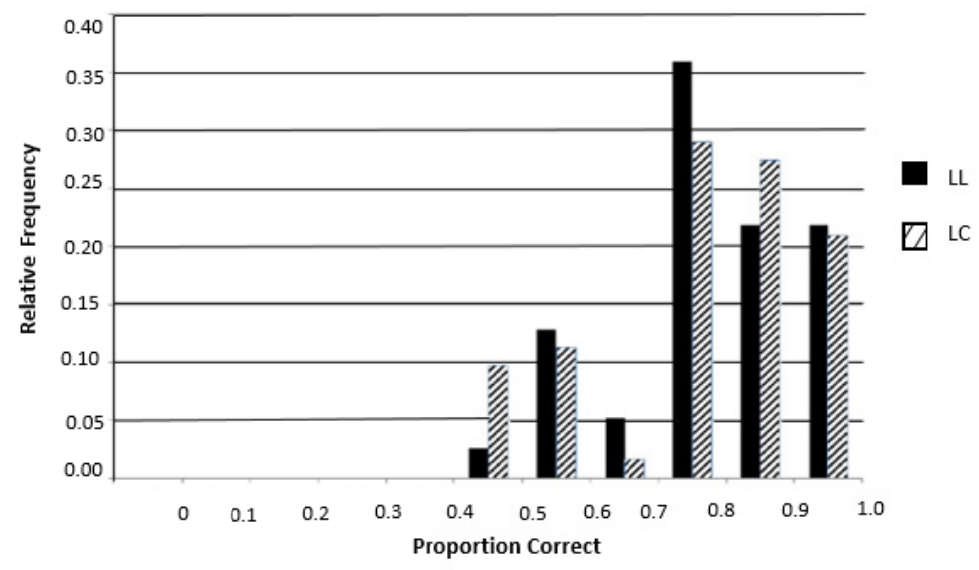

Figure 3. Pattern of Test Performance on Exam Questions ( $N$ for $L L=80$ between two lectures, $N$ for $L C=46$ between two lecture videos; Mann Whitney U test)

\subsection{Student Performance on Exam Questions by the Level of Difficulty}

A. Memory Questions (MQ): LL students answered an average of $71.5 \%$ correctly while LC students answered $73.5 \%$ correctly. However, the difference was not statistically significant (Figure 4).

B. Comprehension Questions (CQ): LL students had an average of 78.3\% while LC students had 75.2\%. However, these numbers were also not statistically different (Figure 4).

C. Application Questions (AQ): LL students answered 82.6\% of relevant exam questions correctly while LC students had an average of $81.7 \%$, although the difference was, once again, not statistically significant (Figure $4)$.

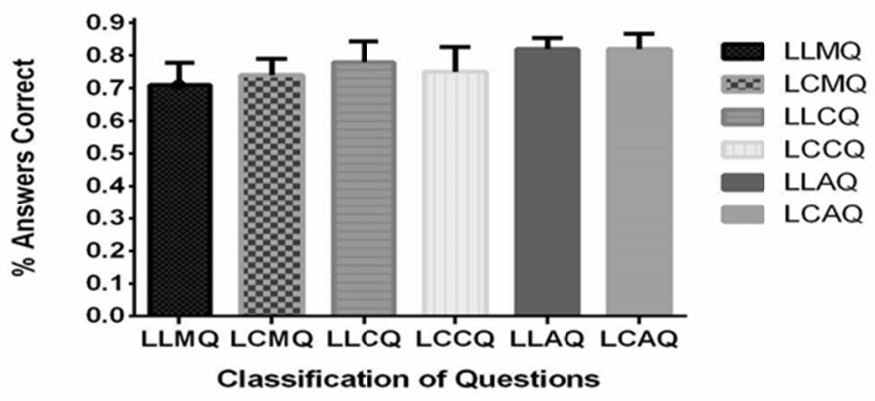

Figure 4. Student Performance on Question types (The number of questions in each group ranged from 6-7; One-way ANOVA test). 


\subsection{Comparison of Students Utilizing Lecture Capture and Their Overall Exam Grade}

In this section, we tested if student performance in the overall exam was affected by LC. As shown in Figures 5 and 6 , both groups, the above $50^{\text {th }}$ percentile and the below $50^{\text {th }}$ percentile (based on the exam scores), utilized recorded lectures. Hence, there was no direct association between the minutes watched and the scores earned on their exams.

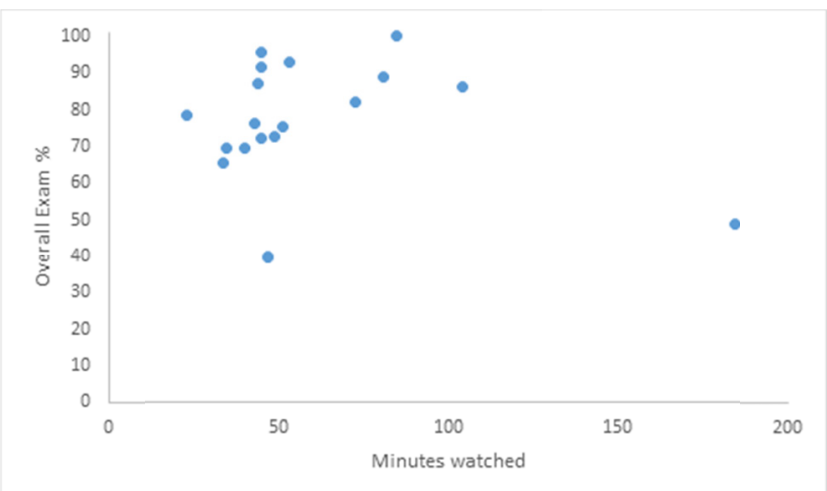

Figure 5. Comparison of Students Utilizing Lecture Capture 1 and Their Overall Exam Grade (Number of students watching lecture video 1 was 19; two-tailed t-test)

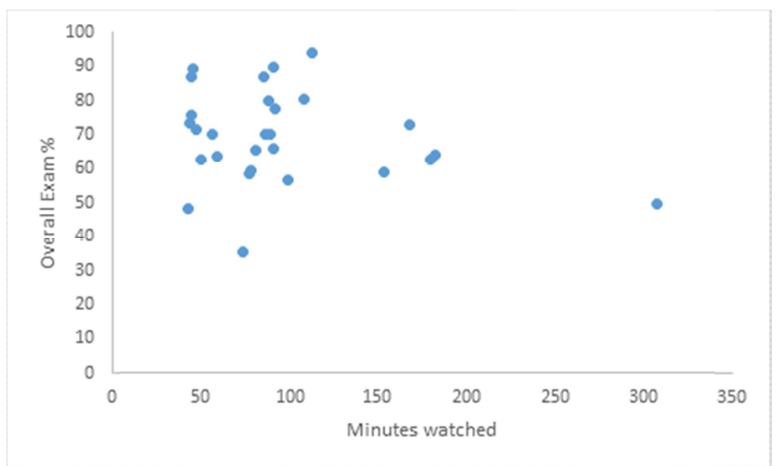

Figure 6. Comparison of Students Utilizing Lecture Capture 2 and Their Overall Exam Grade (Number of students watching lecture video 2 was 27 ; two-tailed t-test)

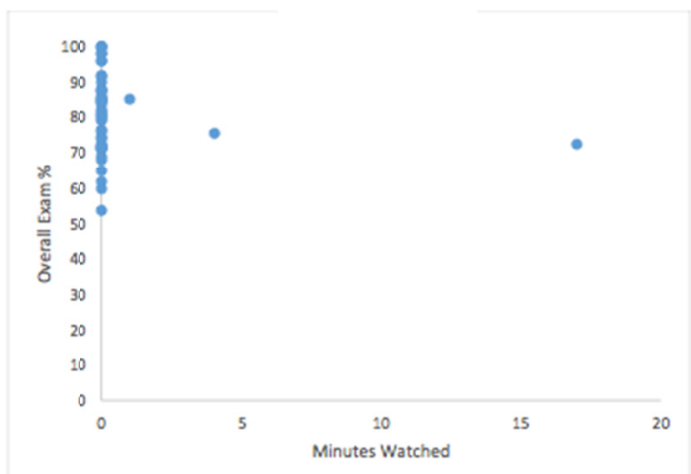

Figure 7. Comparison of Students Who Did not Utilize Lecture Capture 1 and Their Overall Exam Grade (LL for the first lecture was 44; two-tailed t-test) 


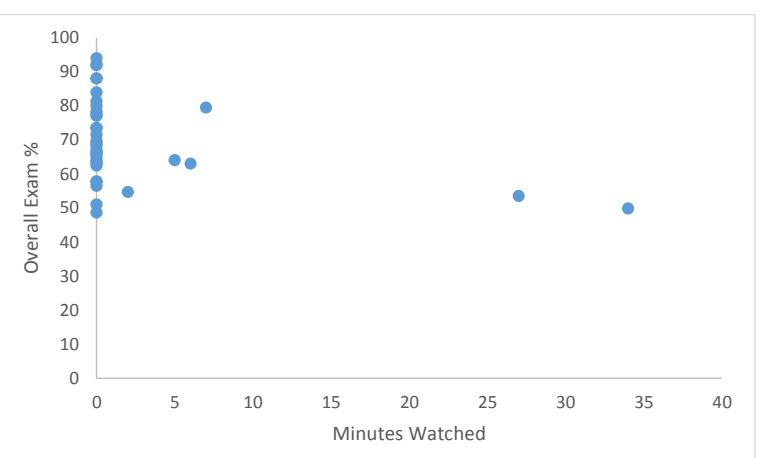

Figure 8. Comparison of Students Who Did not Utilize Lecture Capture 2 and Their Overall Exam Grade (LL for the second lecture was 36; two-tailed t-test)

\section{Discussion}

LC proves viable today as there is an enormous amount of interest in utilizing mobile forms of lecture by students, faculty, and higher institutions for a variety of purposes. Regardless of increasing LC implementation, current research still lacks unanimity on its effects on student performance (Gorisen, Bruggen, \& Jochems, 2012, Prodanov, 2012). One would anticipate that the use of LC, in conjunction with LL, boost student performance on exams (Secker, Bond, \& Grussendorf, 2010). However, our study showed little to no grade improvement on questions that came from the recordings as well as the overall exam, which is consistent with other studies (Euzent, Martin, Moskal, \& Moskal, 2011, Karnad, 2013). For example, a three-year study that was conducted at many universities showed that there was no significant grade improvement associated with LC (Brotherton, \& Abowd, 2004).

Educators have expressed concerns that LC technology may replace or even deplete the educational experience and that student behavior in LL would ultimately change. However, there is no consensus. In fact, in one of the studies, student survey responses unanimously reported little to no change on their behavior and interaction in class (Owston, Lupshenyuk, \& Wideman, 2011). In a separate study, students reported an increased engagement in class with a noticeable improvement in their note taking skills (Marchand, Pearson, \& Albon, 2014). Another major consideration is absenteeism. To dispute this concern, many study results demonstrate that students prefer LL to LC and understand the merits of attending class. Although some studies show a reduction in student attendance, there is still little evidence to support that claim (Cardall, Krupat, \& Ulrich, 2008, Karnad, 2008, Prodanov, 2012). These studies show a disparity in the correlation between absenteeism and recorded lectures and it appears as though more evidence is needed to understand the long-term impact of this new technology in higher education.

When we compared the students with exam scores and the video access to learn if one group chose to utilize the videos more than others, our data tracking suggested that students in all categories, both the low performance (below $50^{\text {th }}$ percentile) and high performance (above $50^{\text {th }}$ percentile) categories, accessed the recordings. Additionally, the length of time students spent on each recording, more than once, did not match with an improved score. A few students watched the video more than once but did not perform well on the exam leading to question whether these students were actually engaged in viewing or left the video open (Figures 5 and 6). On the other hand, one study found that the use of LC as a supplement to LL had little effect on students with high GPAs compared to students with low GPAs although the cause could not be established (Stroup, Pickard, \& Kahler, 2012).

One limitation of this study was the small sample size of 63 students with only $30 \%$ accessing the videos. This is not uncommon and appears as though students have a perception that they would benefit from the real-time recording of lectures, but from the practical aspect, ultimately not all students employ this additional review opportunity (Secker, Bond, \& Grussendorf, 2010). Lack of time, motivation or the assumption that they have already taken good notes could be a factor. On the other hand, some students may have accessed a small portion of the video in order to clarify a specific topic they did not understand in class. This strategy may be efficient for that particular student; however, a majority of students who were in our LL group did not open the video at all. In addition, some students may not have accessed the lecture recordings because this technology is fairly new for the students as they were introduced to this possibility for the very first time. It is important to consider, however, that these lectures came from the fourth and fifth exams, which were the last two exams of the course prior to their final comprehensive exam. Any unfamiliarity with technology in the initial period would have been fixed by this part of the semester. 


\section{Conclusion}

Whether lecture capture videos influence student performance or behavior remain an open question today. From our study, it is apparent that the students in both the above $50^{\text {th }}$ percentile and below $50^{\text {th }}$ percentile used LC although there was no significant difference in student performance. LC utilization once again had no impact whether the questions were at the memorization level of Bloom's taxonomy or at the higher application level. Lecture capture technology may be beneficial for students to replace live lectures under distinct circumstances or alternate study options, but may not prove advantageous in grade enhancement. Future studies with larger student populations perhaps will reveal if LC is simply a flexible option or truly valuable to students in their learning or detrimental in terms of student audience in the classroom.

\section{Acknowledgements}

We sincerely thank Zachary Mussig for his diligence with the instructional technology support and Dr. Claude Gaebelain for his assistance with some of the statistical analysis.

\section{References}

Bloom, B.S., Engelhart, M.D., Furst, E.J., Hill, W.H., \& Krathwohl, D.R. (1956). Taxonomy of Educational Objectives, The classification of educational goals. Handbook I: Cognitive Domain. New York, NY: David McKay Company.

Brotherton, J.A., \& Abowd, G.D. (2004). Lessons learned from eClass: Assessing automated capture and access in the classroom. ACM Transactions on Computer-Human Interaction, 11(2), 121-155.

Cardall, S., Krupat, E., \& Ulrich, M. (2008). Live lecture versus video-recorded lecture: Are students voting with their feet? Academic Medicine, 83, 1174-1178. http://dx.doi.org/10.1186/1472-6920-10-68

Cramer, K.M., Collins, K.R., Snider, D., \& Fawcett G. (2007). The virtual lecture hall: Utilisation, effectiveness and student perceptions. British Journal of Educational Technology, 38, 106-115. http://dx.doi.org/10.1111/j.1467-8535.2006.00598.x

Danielson, J., Preast, V., Bender, H., \& Hassall, L. (2014). Is the effectiveness of lecture capture related to teaching approach or content type? Computers \& Education, 72, 121-131.

Euzent, P.J., Martin, T.L., Moskal, P., \& Moskal, P. (2011) Assessing student performance and perceptions in lecture capture vs. face-to-face course delivery. Journal of Information Technology Education: Research, 10(1), 295-307.

Frey, T. (2015). The future of colleges and universities: Blueprint for revolution. Retrieved December 10, 2015 from http:/www.davinciinstitute.com/papers/the-future-of-colleges-universities-blueprint-for-a-revolution

Gorissen, P., Bruggen, J.V., \& Jochems, W. (2012). Students and recorded lectures: survey on current use and demands for higher education. Research in Learning Technology, 20, 297-311.

Karnad, A. (2015). Student use of recorded lectures: A report reviewing recent research into the use of lecture capture technology in higher education, and its impact on teaching methods and attendance. Retrieved May 28, 2015 from http://eprints.lse.ac.uk/50929/1/Karnad_Student_use_recorded_2013_author.pdf

Marchand, J.P., Pearson, M.L., \& Albon, S.P. (2014). Student and faculty member perspectives on lecture capture in pharmacy education. American Journal of Pharmacological Education, 78(4), 1-7. http://dx.doi.org/10.5688/ajpe78474

Maynor, L.M., Barrickman, A.L., Stamatakis, M.K., \& Elliote, D.P. (2013). Student and faculty perceptions of lecture recording in a doctor of pharmacy curriculum. American Journal of Pharmacological Education, 77(8), 1-7. http://dx.doi.org/10.5688/ajpe778165

McLaren, C.H. (2004). A comparison of student persistence and performance in online and classroom business statistics experiences. Decision Sciences Journal of Innovative Education, 2(1), 1-10. http://dx.doi.org/10.1111/j.0011-7315.2004.00015.x

Navarro, P. (2000). Economics in the Cyber-classroom. Journal of Economic Perspectives, 1(2), $119-132$. http://dx.doi.org/10.1257/jep.14.2.119

Newton, G., Tucker, T., Dawson, J., \& Currie, E. (2014). Use of lecture capture on higher education- Lessons from the 
trenches. Technological Trends, 58, 32-45.

Owston, R., Lupshenyuk, D., \& Wideman, H. (2011). Lecture capture in large undergraduate classes: Student perceptions and academic performance. Internet Higher Education, 14, 262-268. http://dx.doi.org/10.1016/j.iheduc.2011.05.006

Prodanov, V.I. (2012). In-class lecture recording: what lecture capture has to offer to the instructor. Proceedings of the 2012 ASEE PSW Section Conference.

Secker, J., Bond, S., \& Grussendorf, S. (2010). Lecture capture: rich and strange, or a dark art? Retrieved December 11, 2015 from http://eprints.lse.ac.uk/29184

Stroup M.D., Pickard, M.M., \& Kahler, K.E. (2012). Testing the effectiveness of lecture capture technology using prior GPA as a performance indicator. Teacher-Scholar, 4(1), 44-54.

Whitley-Grassi. N., \& Baizer, J.S. (2015). Video lecture capture in physiology courses: Student attendance, video viewing, and correlations to course performance. International Journal of Instructional Technology and Distance Learning, 7(10). 